\title{
CAPÍtulo i \\ LA FILOSOFÍA INSTITUCIONAL: \\ INICIACIÓN A LA FORMACIÓN DE LA IDENTIDAD Y \\ CULTURA INSTITUCIONAL
}

Miguel Moreno $^{1}$
Javier Yate

El presente capítulo pretende responder a las preguntas sobre el porqué y el para qué de la cátedra de Filosofía Institucional, pues desde que ingresa a la comunidad universitaria, el estudiante es ya un tomasino. Su carácter y profesionalidad se modelará por una filosofía, esto es, por una manera de afrontar los problemas y una manera singular de proponer soluciones, tal como se consigna en la misión de la Universidad, la cual nos pide que, desde el humanismo cristiano de Santo Tomás de Aquino, se forme de manera integral a personas en el campo de la educación superior para

1 Miguel Moreno es licenciado en Filosofía y Letras, magíster en Filosofía Latinoamericana y doctorando de la Universidad Santo Tomás. Actualmente se desempeña como coordinador del Departamento de Humanidades y Formación Integral.

2 Javier Yate es licenciado en Filosofía y Letras de la de la Universidad Santo Tomás y magíster en Filosofía Latinoamericana de la misma universidad. En la actualidad se desempeña como docente del Departamento de Humanidades y Formación Integral. 
que respondan de manera crítica, creativa y ética a las exigencias de la vida humana y estén en condiciones de identificar problemas y proponer soluciones.

La formación humanística y el ideal de formación integral en la Universidad Santo Tomás nos enfrentan a dos preguntas: ¿qué es educar?, y ¿qué educar? La Universidad Santo Tomás es una institución que desde el campo de la educación superior y mediante acciones de enseñanza y aprendizaje, investigación y proyección social responde a los fines y objetivos asignados por la ley. Sin embargo, esto mismo lo realizan las muchas instituciones de educación superior, pues esas funciones sustantivas no son propiedad de la Universidad, sino que están contenidas en la Ley 30. Entonces, ¿qué es lo particular?

La respuesta radica en que la Universidad Santo Tomás, como una universidad de Estudio General, hace su apuesta educativa en la formación humanística y apunta al ideal de educación integral para que de este modo la sociedad reciba una persona formada de una manera especial que se distingue de otras personas y profesionales. Pero ¿podrían ampliarse un poco esos elementos? Es decir, ¿qué es universidad de Estudio General?, ¿qué es formación humanística?, ¿a qué se refiere con ideal de formación integral?

El Estudio General surgió con la universidad en la Edad Media. Estas instituciones debían tener la capacidad de recibir estudiantes de cualquier nación, debían tener maestros especializados para cada una de las áreas de conocimiento y, finalmente, debían enseñar en las facultades mayores, en ocasiones fueron encargadas del trívium y del cuadrivium. ${ }^{3}$ Como la nuestra, Bolonia, Oxford, París, Cambridge, Salamanca y la Universidad Johannes Gutenberg, en Alemania, se reconocen hoy en día como universidades de Estudio General.

Ahora bien, cuando se habla de Universidad de Estudio General, se hace referencia al diálogo de saberes, es decir que considera imprescindible la formación de todos, en una base común de carácter humanista, que eleve a los futuros profesionales a la altura de su cultura y de su historia, y que sitúe la ciencia y el conocimiento en su relación funcional con la construcción total de la vida humana en el mundo. ${ }^{4}$

Fundamentada en su carácter de Universidad de Estudio General, la Universidad Santo Tomás ha enfatizado siempre su diferencia frente al modelo universitario politécnico: su

3 Alfonso Borrero Cabal, Idea de la universidad medieval: notas y funciones institucionales. La autonomía (Bogotá: ASCUN, 1985).

4 Fray Franklin Buitrago Rojas O. P., El Studium Generale: un lugar de encuentro entre la revelación y las ciencias del hombre, Optantes: Revista de los Frailes Estudiantes Dominicos de Colombia Vol. $12 \mathrm{~N}^{\circ} 24$ (2003): 40-48. 
naturaleza le exige cultivar una visión humanista propia, una cosmovisión filosófico-teológica que fundamente y oriente los distintos currículos profesionales. ${ }^{5}$

Gracias al Estudio General es posible que el estudiante tomasino busque entender la realidad de una manera crítica y ética más completa, pueda actuar responsablemente y aporte soluciones que favorezcan la convivencia. En otras palabras, "formar en la ciencia, en la conciencia y para la presencia”, porque los tomasinos líderes son los que piensan su ciencia, le dan sentido a sus actos y siempre deben pensar en el bien-estar de las personas y de la sociedad. ${ }^{6}$

En este sentido, hablar de formación humanística en el contexto de la universidad dominicana de Estudio General se refiere a ese estudio riguroso y metódico de todos los campos y perspectivas de la realidad en donde la dignidad de lo humano se impone sobre los demás saberes. Así las cosas, si bien existen muchos humanismos, en la USTA se opta por el cristiano dominicano a la manera de Santo Tomás: humanismo cristiano tomista. ¿Y esto qué significa?

Significa que creemos firmemente en el diálogo crítico entre ciencia, filosofía y teología, porque si optamos exclusivamente por la filosofía, caemos en dogmatismos; si nos inclinamos únicamente a la dimensión trascendente caemos en fanatismos y si elegimos de manera preponderante la ciencia, deshumanizamos. El diálogo reconoce afirmar la dignidad de lo humano y la necesidad del desarrollo armónico de todas las dimensiones, habilidades, destrezas y capacidades de las personas, refuerza la autonomía del ser humano y su corresponsabilidad con el ambiente, la sociedad, la cultura y los desarrollos del mundo actual.

Este humanismo, en diálogo con todos los demás saberes, culturas, antihumanismos y otros humanismos, ${ }^{7}$ inspira las tareas y las funciones sustantivas de la Universidad; de allí que el objetivo fundamental sea "promover la formación integral de las personas" en cuanto ser racional, que es capaz de dirigir su vida e intervenir como agente de convivencia, esto se llama en términos tomistas prudencia, es decir, lograr esa madurez racional y esa capacidad autodirectiva. "Estado de virtud" es, en otras palabras, alcanzar la "formación integral", 9 que es a lo que apuntan las actividades de formación en la Universidad. En este sentido, se comprende que la formación

5 Universidad Santo Tomás. Proyecto Educativo Institucional PEI. Bogotá: Universidad Santo Tomás, 2004, 42.

6 Eduardo Alberto Gómez Bello y Miguel Moreno Lugo, Filosofía y cultura institucional, (Bogotá: Ediciones USTA, 2015), 34.

7 Ibíd., 23.

8 Ibíd., 23.

9 Ibíd., 24. 
integral no se contraponga o se separe de la formación del profesional. "La primera se completa con la segunda, y esta cobra sentido pleno en el marco de la primera" ${ }^{10}$

De lo anterior se desprende que las profesiones impartidas en esta Universidad son orientadas desde el humanismo cristiano tomista, en diálogo abierto con modelos de desarrollo, perspectivas económicas, ideologías políticas, sistemas sociales específicos e incluso con otros saberes y posturas religiosas. Todos estos son ámbitos con los cuales se dialoga desde la comprensión humanística de la Universidad y hacen parte de los saberes de las disciplinas. Sin la comprensión profunda del humanismo que sostiene la Universidad, cada facultad formaría profesionales desde perspectivas particulares, corriendo el peligro de alejarse de la misión y perder el sello distintivo — humanismo cristiano tomista - de la Universidad.

El Modelo Pedagógico Institucional define la educación como un proceso que abarca todos los niveles de la vida, desde la crianza, el desarrollo psicológico y el perfeccionamiento gradual de las potencialidades espirituales (inteligencia y voluntad). ${ }^{11}$ Se trata por tanto de un proceso holístico de perfeccionamiento y desarrollo integral del hombre.

En la Universidad Santo Tomás, este proceso de enseńanza y aprendizaje se encuadra en el espacio de la filosofía de la educación de Tomás de Aquino, la cual tiene como fin un estado de perfección en el hombre mediante la promoción, la instrucción y la nutrición, traducción de la palabra educatio. ${ }^{12}$

En el contexto del modelo educativo, en Tomás de Aquino es necesario diferenciar entre educare y edúcere, el primero referido a alumnus y el segundo a studens. Educare traduce criar, alimentar, hacer crecer, educar física y moralmente, de allí que alumnus, que contrario a lo que se traduce comúnmente como "sin luz", es el que es nutrido, pues deviene de Álere (alimentar, nutrir), Alimentum y Aimentarius. Edúcere, por su parte, significa conducir de abajo arriba, levantar, hacer pasar, extraer, conducir, citar, hacer salir, hacer salir del cascarón, por ello Studens, que significa el que se ocupa seriamente y Studere, poner sus miras en, aplicarse a, buscar una cosa con diligencia, concentrase (con voluntad y autonomía). ${ }^{13}$

10 Ibíd., 63.

11 Vicerrectoría Académica, Modelo Educativo Pedagógico (Bogotá: Universidad Santo Tomás, 2009).

12 Antonio Millán Puelles, La formación de la personalidad humana (Madrid: Ediciones Rialp S.A., 1963).

13 David Vásquez Ramos, La virtud de la studiositas y el conocimiento. Un estudio desde Tomás de Aquino (Pamplona: Universidad de Navarra, 2009). 
Entonces, ante la pregunta sobre para qué formar en una Filosofía Institucional en la perspectiva de la Universidad Santo Tomás, la respuesta está en el saber que tiende al bien, que es su único fin. Facientes Veritatem, ${ }^{14}$ la expresión del contemplar dominicano que no es para sí, sino para los demás, Contemplari et contemplata allis tradere, pues el dar implica disposición y preparación. ${ }^{15}$

En un mundo como el de hoy, que responde desde lo útil, lo productivo y lo rentable a las exigencias de la vida, la Universidad, sin renunciar a lo anterior, hace una apuesta total y radical por las humanidades como elemento fundamental de la formación en términos de la consecución de ese fin, que como se dijo hace unos momentos, es el ideal de formación integral. Mientras hoy domina en el discurso el concepto de competencias laborales, la Universidad, sin desconocer esta realidad, se arriesga a hablar de las dimensiones de la acción (comprender, hacer, obrar y comunicar).

\section{Tabla 1}

\section{Comprender}

\section{Visión racional estructural de la realidad}

Análisis, interpretación, síntesis y argumentación del conocimiento, de los principios, conceptos, teorías, lenguajes y métodos y de la capacidad de recontextualización de los núcleos problémicos de acuerdo a los propósitos de formación institucional y profesional.

\section{Hacer}

Acción transformadora y productora

De las habilidades y destrezas propias de la cátedra, manejo de tecnologías e instrumentos para el desarrollo de la asignatura, habilidades para formular y evaluar proyectos.

14 Universidad Santo Tomás, Proyecto Educativo Institucional PEI, Op. Cit., 92.

15 Fray José de Jesús Sedano González, O.P., Pedagogía de la respuesta. Horizonte tomasiano para la formación integral de la persona (Bucaramanga: Universidad Santo Tomás, 2012) 


\section{Obrar}

\section{Acción conforme a valores éticos}

Respeto y solidaridad, sentido crítico-propositivo y resignificación de aprendizajes desarrollados a partir de la interacción con el otro, apertura y reconocimiento del otro como interlocutor válido, y desarrollo de la sensibilidad y la responsabilidad social.

\section{Comunicar}

\section{Interacción a través de diferentes} lenguajes

Escucha, expresión verbal clara, expresión escrita, capacidad para expresar las inquietudes propias, dominio de lenguajes específicos de las cátedras, capacidad para presentar proyectos, uso de los lenguajes multimedia, manejo de recursos simbólicos y capacidad para el trabajo en equipo.

Fuente: tabla construida por los autores a partir de Política curricular para programas académicos. Universidad Santo Tomás, $2004^{16}$

De este modo, la formación en Filosofía Institucional recoge la misión, los principios, valores, objetivos y funciones de la Universidad, ${ }^{17}$ en consonancia con el lema "Primero personas, luego profesionales".

Ahora bien, todo este ideario, pedagógicamente, se puede expresar así: la realidad se nos presenta problemática, esto es, como un conjunto de problemas y necesidades que nos obligan a generar preguntas problematizadoras, con otros saberes y actores que nos permitan ampliar el campo comprensivo de la misma. Estas preguntas son la ruta para acceder al objeto del conocimiento; son preguntas que enfocan, permiten optar, enfrentar y afrontar esas problemáticas de acuerdo con la Filosofía Institucional. Cuando se logra ese proceso de pedagogizar las problemáticas, se alcanzan núcleos problémicos que dan unidad de sentido y hacen posible aterrizar el objeto de enseñanza curricularmente en el aula de clase.

Todo este engranaje exige un especial interés en el contexto de la celebración de los 50 años de restauración de la Universidad, con sus "435 años de formación humanista: Profesionales humanistas que transforman al país", ya que nos invita a hacer una revisión de cómo se ha tratado el tema de la formación en la Filosofía Institucional.

Para el año 1968, el padre Joaquín Zabalza Iriarte, O. P., dirigía la Facultad de Filosofía, además de la jefatura del Departamento de Cultura Teológica, instancia que ofrecía el curso

16 Universidad Santo Tomás, Politica curricular para programas académicos (Bogotá: Universidad Santo Tomás, 2004), 12-27.

17 Universidad Santo Tomás, Plan General de Desarrollo 2011-2015 (Bogotá: Universidad Santo Tomás, 2004), 8-11 
"Tomismo"; este curso se mantuvo para las reformas administrativas del año 1973, 1974 y 1993. Es en el año 2005 cuando el Padre Orlando Rueda Acevedo, O. P., en calidad de Vicerrector, replantea el tema de la cátedra y toma el nombre de Filosofía Institucional. El director del Departamento de Humanidades de entonces, Carlos Julio Flórez Márquez, delegó a los doctores Eudoro Rodríguez y Tomás Sánchez para que diseñen el programa, obteniéndose dos perspectivas: un programa enfocado a las significaciones del tomismo hoy en día y otro enfocado a la formación del joven universitario ${ }^{18}$.

Para hermanar estas perspectivas, se optó por crear cinco módulos que hacían el recorrido de la siguiente manera: problématica de la juventud universitaria; Tomás de Aquino: vida, retos y contextos de su tiempo; Tomás de Aquino: las grandes controversias de su tiempo; el tomismo y su presencia ideológica en América Latina en la historia latinoamericana; y por último, filosofía educativa de Tomás de Aquino.

Por su carácter de actualidad universitaria, esta cátedra ha tenido que revisarse constantemente; por ello, los coordinadores Dalia Carreño, Didier Santiago y Jairo Sandoval le han dado impulso desde diferentes perspectivas, como la publicación de módulos, implementación de las TIC, vinculación a redes sociales, interacción USTA Colombia, entre otros. Para el año 2010 se presentaba la cátedra de la siguiente manera:

El primer paso de la formación humanística de la Universidad Santo Tomás.

Su contenido está definido por la filosofía que anima a la misma institución y que se encuentra recogida en la propuesta pedagógica expuesta en el PEI, consistente en la búsqueda y construcción de la verdad sobre los fundamentos del humanismo cristiano de Tomás de Aquino. Así, en esta asignatura se hace una introducción desde las generalidades de la universidad hasta los elementos más específicos de su propuesta filosófica de considerarse como un centro de Estudio General. Su importancia radica en el vínculo que se establece entre la problemática de la juventud actual y el proyecto que la USTA ofrece como ideal de formación que se ajusta a las diferentes opciones profesionales con las cuales entramos y nos identificamos. [...] La cátedra de Filosofía Institucional, como su nombre lo indica, es el ideario, la piedra angular de su teoría pedagógica. ${ }^{19}$

18 Universidad Santo Tomás, Libro 50 años de restauración [manuscrito] (Bogotá: Universidad Santo Tomás, 2015).

19 Universidad Santo Tomás, El Departamento de Humanidades y Formación Integral en la Universidad Santo Tomás (Bogotá: Universidad Santo Tomás, 2010). 
Actualmente, la cátedra de Filosofía Institucional pretende ser una dinámica de inicio a la vida universitaria, especialmente dirigida al sector juvenil, que se enfrenta hoy a múltiples problemas e interrogantes. Trabaja trasversalmente la reflexión sobre el proyecto de vida, es un espacio académico sui generis y se constituye en escenario de frontera que encarna la posibilidad de integrar una intertextualidad entre los diferentes campos de conocimiento. ${ }^{20}$

\section{Conclusiones}

Esta cátedra es la primera que responde a la Misión Institucional, por ello, desde el primer momento su énfasis se dirige no solo a lo anteriormente dicho, sino que busca también la formación en lo crítico, creativo y ético. Para lograr el desarrollo de la actitud crítica se plantean en el syllabus núcleos con problemas que enfrentan al estudiante con su realidad próxima, aquella que lo impacta directamente y le permite realizar cuestionamientos que luego ampliará en la formación humanística de la universidad. La actitud creativa en esta cátedra se desarrolla con la iniciación a la Metodología Problématizadora, la cual enfrenta al neotomasino a nuevas formas de percibir la realidad y de proponer soluciones a la misma. Por último, su componente ético no se resuelve como una asignatura que cursará en algún momento de la carrera; por el contrario, esta dimensión busca que el alumno sea responsable y comprometido de su crítica y de su propuesta de solución a las problemáticas que ha logrado discernir en su proceso pedagógico.

Finalmente, la cátedra pretende introducir al estudiante neotomasino en la dinámica de la formación humanística, académica e investigativa de la Universidad Santo Tomás, en consonancia con el pensamiento y el espíritu de Tomás de Aquino, su filosofía educativa y su visión integral de la realidad.

20 Martha Nussbaum, El cultivo de la humanidad: una defensa clásica de la reforma en la educación liberal (Barcelona: Andrés Bello, 2001). 


\section{Referencias}

Borrero Cabal, Alfonso. Idea de la universidad medieval: notas y funciones institucionales. La autonomía. Bogotá: ASCUN, 1985.

Buitrago Rojas. Fray Franklin, O. P. El Studium Generale: un lugar de encuentro entre la revelación y las ciencias del hombre. Optantes: Revista de los Frailes Estudiantes Dominicos de Colombia Vol. $12 \mathrm{~N}^{\circ} 24$ (2003): 40-48.

Gómez Bello, Eduardo Alberto, y Miguel Moreno Lugo. Filosofía y cultura institucional. Bogotá: Ediciones USTA, 2015.

Millán Puelles, Antonio. La formación de la personalidad humana. Madrid: Ediciones Rialp S.A., 1963.

Nussbaum, Martha. El cultivo de la humanidad: una defensa clásica de la reforma en la educación liberal. Barcelona: Andrés Bello, 2001.

Sedano González, Fray José de Jesús, O. P. Pedagogía de la respuesta. Horizonte tomasiano para la formación integral de la persona. Bucaramanga: Universidad Santo Tomás, 2012.

Universidad Santo Tomás. Plan General de Desarrollo 2011-2015. Bogotá: Universidad Santo Tomás, 2004.

Universidad Santo Tomás. Política curricular para programas académicos. Bogotá: Universidad Santo Tomás, 2004.

Universidad Santo Tomás. Proyecto Educativo Institucional PEI. Bogotá: Universidad Santo Tomás, 2004. Universidad Santo Tomás. El Departamento de Humanidades y Formación Integral en la Universidad Santo Tomás. Bogotá: Universidad Santo Tomás, 2010.

Universidad Santo Tomás. Libro 50 años de restauración [manuscrito]. Bogotá: Universidad Santo Tomás, 2015.

Vásquez Ramos, David. La virtud de la studiositas y el conocimiento. Un estudio desde Tomás de Aquino. Pamplona: Universidad de Navarra, 2009.

Vicerrectoría Académica. Modelo Educativo Pedagógico. Bogotá: Universidad Santo Tomás, 2009. 
